\title{
Unusual Allylpalladium Carboxylate Complexes: Identification of the Resting State of Catalytic Enantioselective Decarboxylative Ketone Allylic Alkylation Reactions*
}

\author{
Nathaniel H. Sherden, Douglas C. Behenna, Scott C. Virgil, and Brian M. Stoltz \\ The Arnold and Mabel Beckman Laboratories of Chemical Synthesis and the Caltech Center for \\ Catalysis and Chemical Synthesis, Division of Chemistry and Chemical Engineering, California \\ Institute of Technology, 1200 E. California Boulevard MC 101-20, Pasadena, CA 91125 (USA), Fax: \\ (+1) 626-395-8436 \\ Brian M. Stoltz: stoltz@caltech.edu
}

\begin{abstract}
Palladium poprocks: Hold on to your $\mathrm{CO}_{2}$ ! Enantioselective Pd-catalyzed decarboxylative alkylation of ketone enolates proceeds via $\eta^{1}-\sigma$-allyl Pd-carboxylate complexes by slow loss of $\mathrm{CO}_{2}$.
\end{abstract}

\section{Keywords}

allylic alkylation; asymmetric catalysis; palladium; carboxylate ligands; reaction mechanism

\begin{abstract}
We recently developed a series of catalytic enantioselective allylic alkylation reactions of cyclic ketone enolates that proceed by decarboxylation of allyl carbonates and $\beta$-ketoesters (Scheme 1).[1] These robust reactions proceed in the presence of a wide array of functionality and steric hindrance, in a variety of solvents, and have an unusually high tolerance to water. [2] To gain further experimental insight into this chemistry, we embarked on a mechanistic study [3] that has now resulted in the isolation and full characterization of complex 1, the resting state of a prototypical reaction. In addition to describing the identification of this unusual complex, we discuss its potential implications for Pd-catalyzed decarboxylative asymmetric alkylation reactions and other related transformations.

Initially, we sought to follow the catalytic reaction of a standard $\beta$-ketoester substrate, $( \pm)-2$, by ${ }^{31} \mathrm{P}$ NMR. Combining $(S)-t-\mathrm{BuPHOX}(3)$ and $\mathrm{Pd}_{2}(\mathrm{dba})_{3}$ in a 2.6: 1 ratio at room temperature for $30 \mathrm{~min}$ as specified in our standard alkylation procedure,[1] yielded a single new resonance at $18.8 \mathrm{ppm}$ along with the signal for free ligand (3) at $-5.95 \mathrm{ppm}$ (Figure 2, A). The addition of $\beta$-ketoester $( \pm)-2$ resulted in the complete disappearance of the resonance at $18.8 \mathrm{ppm}$ and produced a long-lived resonance at 30.9 ppm (Figure 2, B). As the reaction forming ketone 4
\end{abstract}

\footnotetext{
*** The authors wish to thank NIH-NIGMS (R01 GM 080269-01), Abbott Laboratories, Amgen, Merck, Bristol-Myers Squibb, Boehringer Ingelheim, the Fannie and John Hertz Foundation (predoctoral fellowship to DCB), the Gordon and Betty Moore Foundation, and Caltech for financial support. Mr. Lawrence Henling and Dr. Michael Day are gratefully acknowledged for X-ray crystallographic structural determination. The Bruker KAPPA APEXII X-ray diffractometer was purchased via an NSF CRIF:MU award to the California Institute of Technology, CHE-0639094. Professors J. E. Bercaw, R. H. Grubbs, S. E. Reisman, W. A. Goddard III, and Dr. J. A. Keith are acknowledged for helpful discussions. Dr. David Vander Velde and Dr. Scott Ross are thanked for helpful assistance related to NMR.

Correspondence to: Brian M. Stoltz, stoltz@caltech. edu.

Supporting information for this article is available on the WWW under http://www.angewandte.org or from the author.
} 
neared completion, the long-lived intermediate slowly reverted to the original resonance at 18.8 ppm (Figure 2, C).[4]

We proceeded to isolate and characterize the complex corresponding to the long-lived resonance at $30.9 \mathrm{ppm}$ and identified it as 1 (Figure 1). Despite the apparent abundance of this complex in solution under the catalytic reaction conditions, $\mathbf{1}$ proved challenging to isolate due to air sensitivity and thermal instability well below $24^{\circ} \mathrm{C}$ both in solution and as a solvent-free solid.[5] Interestingly, impure samples of $\mathbf{1}$ visibly expel a gas (presumably $\mathrm{CO}_{2}$ ) in the solid state and effervesce in solvent.[6] After extensive experimentation, crystals of high purity and reasonable stability were isolated and crystallographically characterized as a mixture of diastereomers resulting from the use of racemic $\beta$-ketoester $\mathbf{2}$. Complex $\mathbf{1}$ is a square planar 16-electron species with a $\sigma$-bound, $\eta^{1}$-allyl ligand trans to nitrogen and a $\beta$-ketocarboxylate ligand trans to phosphorous. By contrast, the analogous $\mathrm{Pd}(\mathrm{PHOX})$ allyl $\cdot \mathrm{PF}_{6}$ cationic complex displays $\eta^{3}$ - $\pi$-allyl bonding in the solid state[3,6,7] as do related structures in solution.[8]

The structure of intermediate 1 reveals that it must form after oxidative addition, but prior to decarboxylation. Since $\mathbf{1}$ is the only observable species during the course of the catalytic reaction, it represents the catalyst resting state and suggests that the rate-determining step for the allylic alkylation of $\beta$-ketoester substrates is decarboxylation.[4] This is consistent with our previously reported kinetic data for the overall reaction that shows a first-order dependence on catalyst concentration and an apparent zero-order dependence on the substrate concentration.[3]

The structure of palladium complex $\mathbf{1}$ is noteworthy. The arrangement of the allyl and carboxylate ligands in intermediate $\mathbf{1}$ is similar to that of a structure previously calculated by DFT methods for a palladium allyl enolate complex (6).[3] Importantly, enolate $\mathbf{6}$ was described as the penultimate intermediate prior to the key carbon-carbon bond-forming reductive elimination step in the calculated inner-sphere mechanistic pathway (Figure 3). The high degree of structural similarity between intermediate $\mathbf{1}$ and complex 6 lends credence to this key calculated structure, and may also represent the best isolable experimental model system for the calculated intermediate.

The crystal structure of intermediate $\mathbf{1}$ is not only the first example in the CSD consisting of a palladium species with a $\beta$-ketocarboxylate ligand, but it is also the first X-ray structure of any transition metal complex with a $\sigma$-bound allyl cis to a carboxylate ligand.[9] Given the enormous number of transition metal-catalyzed reactions involving allylic acetates and carbonates, this structure may have important mechanistic implications not only for the immediately related decarboxylative allylic alkylation reactions, $[1,10]$ but also for palladium catalyzed allylic oxidations,[11,12] palladium catalyzed 1,4-diacetoxylation,[11,13] and late transition metal-catalyzed decarboxylative reactions in general. With this in mind, we synthesized and crystallographically characterized the neutral $\eta^{1}$-allyl(PHOX)Pd(OAc) (7,Figure 4). Similar to carboxylate 1, complex $\mathbf{7}$ is a 4-coordinate $\mathrm{Pd}(\mathrm{II})$ square planar species bearing a trans relationship of the phosphine and acetate. Despite its simplicity and central nature to many catalytic pathways, this canonical oxidative addition adduct of allyl acetate and $\mathrm{L}_{\mathrm{n}} \mathrm{Pd}(0)$ has not been previously characterized.[14] In light of the availability of $\eta^{1}$-allyl complexes 1 and $\mathbf{7}$, it may be reasonable to consider analogous neutral intermediates in a variety of studies.[15]

With the catalyst resting state of the catalytic cycle identified, we studied the general reactivity of complex $\mathbf{1}$. After $40 \mathrm{~min}$ in anhydrous THF at $24{ }^{\circ} \mathrm{C}$, samples of intermediate $\mathbf{1}$ convert to the allylic alkylation product $\mathbf{4}$, in $89 \%$ ee, which is consistent with the enantioselectivity observed in catalytic reactions conducted under our standard conditions (Scheme 2).[1] Allowing this thermal decomposition to occur in the presence of free dba ligand generates 
complex 5 (Scheme 2).[16] Phosphorous-31 NMR indicated that this complex (5) was identical to the phosphorus-containing compound previously observed in the ${ }^{31} \mathrm{P}$ NMR study described above (Figure 2, A and C). Additionally, complex $\mathbf{5}$ can be formed independently by mixing $\mathrm{Pd}_{2}(\mathrm{dba})_{3}$ with $(S)-t$-BuPHOX (3), suggesting that complex $\mathbf{5}$ is the initial adduct in our, as well as other related, allylic alkylation systems,[10a,b,e] and is the predominant palladiumcontaining species in the absence of substrate.

We proceeded to isolate and characterize complex $\mathbf{5}$, which was assigned by X-ray analysis to be monomeric $\mathrm{Pd}(\mathrm{PHOX})(\mathrm{dba})$ (Figure 5). Isolated $\mathbf{5}$ is a competent catalyst for the asymmetric alkylation reaction providing yields and enantiomeric induction analogous to that of our previously published procedures.[1,6]

A mechanistic picture for the transformation $( \pm)-\mathbf{2} \rightarrow(S)$-4 begins to emerge with these results in hand (Scheme 3). Initial formation of a $\mathrm{Pd}(\mathrm{PHOX})(\mathrm{dba})(\mathbf{5})$ precedes substrate coordination and oxidative addition to form carboxylate $\mathbf{1}$, the resting state of the catalytic cycle. Turnoverlimiting decarboxylation produces enolate $\mathbf{6}$, which undergoes rapid $\mathrm{C}-\mathrm{C}$ bond forming and enantiodetermining reductive elimination to form $(S)-\mathbf{4}$ and a palladium species capable of engaging further substrate to continue the cycle. Alternatively, upon consumption of substrate $( \pm)$-2, complexation with dba produces complex 5 again.

In summary, we have experimentally detailed the mechanism of the early stages of our enantioselective allylic alkylation reaction. We have isolated and characterized all of the ${ }^{31} \mathrm{P}$ NMR-observable intermediates from the catalytic alkylation reaction of $\beta$-ketoester $( \pm)-2$, including $c i s-\eta^{1}-\sigma$-allyl intermediate $\mathbf{1}$. We believe this unique structure (1) and the acetate counterpart (7) are of potential mechanistic significance to a broad range of reactions. Experimental mechanistic investigations into the decarboxylation, bond-forming, and stereoselective steps of our allylic alkylation reaction are currently underway.

\section{Supplementary Material}

Refer to Web version on PubMed Central for supplementary material.

\section{References}

1. a) Mohr JT, Stoltz BM. Chem-Asian J 2007;2:1476-1491. [PubMed: 17935094] b) Mohr JT, Behenna DC, Harned AM, Stoltz BM. Angew Chem 2005;117:7084-7087.Angew Chem Int Ed 2005;44:69246927. c) Behenna DC, Stoltz BM. J Am Chem Soc 2004;126:15044-15045. [PubMed: 15547998] d) Seto M, Roizen JL, Stoltz BM. Angew Chem 2008;120:6979-6982.Angew Chem Int Ed 2008;47:6873-6876.

2. For instance, the addition of 0.55 equiv $\mathrm{H}_{2} \mathrm{O}$ to a typical reaction results in only marginal loss of yield and ee $(<2 \%$ each). See supporting information for details.

3. Keith JA, Behenna DC, Mohr JT, Ma S, Marinescu SC, Oxgaard J, Stoltz BM, Goddard WA III. J Am Chem Soc 2007;129:11876-11877. [PubMed: 17824701]

4. To corroborate our investigation between all three variants of our allylic alkylation reaction, analogous ${ }^{31}$ P NMR experiments were performed for the equivalent conversion of allyl enol carbonate and silyl enol ether substrates to ketone $\mathbf{4}$ yielding similar results.[6]

5. At $24{ }^{\circ} \mathrm{C}$, carboxylate 1 has a $t_{1 / 2}=7.3 \mathrm{~min}$ in THF- $d_{8}$.

6. See supporting information for details.

7. The related (i-PrPHOX)Pd(diphenylallyl)Cl displays a similar 4-coordinate arrangement with an $\eta^{1}$ allyllic unit. For this complex and a discussion of other, rare $\eta^{1}$-allyl.Pd complexes, see: Kollmar M, Helmchen G. Organometallics 2002;21:4771-4775.

8. For comprehensive discussions, see: a) Kollmar M, Goldfuss B, Reggelin M, Rominger F, Helmchen G. Chem-Eur J 2001;7:4913-4927. b) Liu S, Müller JFK, Neuburger M, Schaffner S, Zehnder M. J Organomet Chem 1997;549:283-293. 
9. Literature examples of transition metal complexes with a $\sigma$-bound allyl cis to a carboxylate ligand are limited to a single ruthenium and a single rhodium complex that are characterized by other methods See: a) Planas JG, Marumo T, Ichikawa Y, Hirano M, Komiya S. J Mol Catal A Chem 1999;147:137154. b) Payne MJ, Cole-Hamilton DJ. J Chem Soc Dalton Trans 1997:3167-3175.

10. a) Bélanger É, Houzé C, Guimond N, Cantin K, Paquin JF. Chem Commun 2008:3251-3253. b) Bélanger É, Cantin K, Messe O, Tremblay M, Paquin JF. J Am Chem Soc 2007;129:1034-1035. [PubMed: 17263376] c) Waetzig SR, Rayabarapu DK, Weaver JD, Tunge JA. Angew Chem 2006;118:5099-5102.Angew Chem Int Ed 2006;45:4977-4980. d) Trost BM, Bream RN, Xu J. Angew Chem 2006;118:3181-3184.Angew Chem Int Ed 2006;45:3109-3112. e) Nakamura M, Hajra A, Endo K, Nakamura E. Angew Chem 2005;117:7414-7417.Angew Chem Int Ed 2005;44:7248-7251.f) Trost BM, Xu J. J Am Chem Soc 2005;127:2846-2847. [PubMed: 15740108]

11. a) Grennberg H, Langer V, Bäckvall JE. J Chem Soc Chem Commun 1991:1190-1192. b) Bäckvall JE, Hopkins RB, Grennberg H, Mader MM, Awasthi AK. J Am Chem Soc 1990;112:5160-5166.

12. a) Moiseev II, Vargaftik MN. Coord Chem Rev 2004;248:2381-2391. b) Hansson S, Heumann A, Rein T, Åkermark B. J Org Chem 1990;55:975-984. c) Byström SE, Larsson EM, Åkermark B. J Org Chem 1990;55:5674-5675. d) Åkermark B, Hansson S, Rein T, Vågberg J, Heumann A, Bäckvall JE. J Organomet Chem 1989;369:433-444.

13. Bäckvall JE, Byström SE, Nordberg RE. J Org Chem 1984;49:4619-4631.

14. For structures of $\eta^{3}$-allylic $\mathrm{Pd}, \mathrm{Pt}$, and Ni complexes with noncoordinating trifluoroacetate and bicarbonate counterions, see: a) Böttcher L, Scholz A, Walther D, Weisbach N, Görls H. Z Anorg Allg Chem 2003;629:2103-2112. b) Dervisi A, Edwards PG, Newman PD, Tooze RP, Coles SJ, Hursthouse MB. J Chem Soc Dalton Trans 1999:1113-1120. c) Jacob V, Weakley TJR, Haley MM. Organometallics 2002;21:5394-5400. d) Pawlas J, Nakao Y, Kawatsura M, Hartwig JF. J Am Chem Soc 2002;124:3669-3679. [PubMed: 11929257] e) Ozawa F, Son T-i, Ebina S, Osakada K, Yamamoto A. Organometallics 1992;11:171-176.

15. Neutral $\eta^{2}$-olefin complexes have been previously postulated to be long-lived states, prior to oxidative addition, in related allylic alkylations. It has also been assumed that the product of oxidative addition leads directly to a cationic $\eta^{3}$-allyl complex. For examples, see: a) Evans LA, Fey N, Harvey JN, Hose D, Lloyd-Jones GC, Murray P, Orpen AG, Osborne R, Owen-Smith GJJ, Purdie M. J Am Chem Soc 2008;130:14471-14473. [PubMed: 18839958] b) Amatore C, Gamez S, Jutand A. Chem-Eur J 2001;7:1273-1280.

16. The enantioselectivity of the reaction to produce ketone $\mathbf{4}$ is insensitive to the presence of 3.0 equiv dba in solution. 


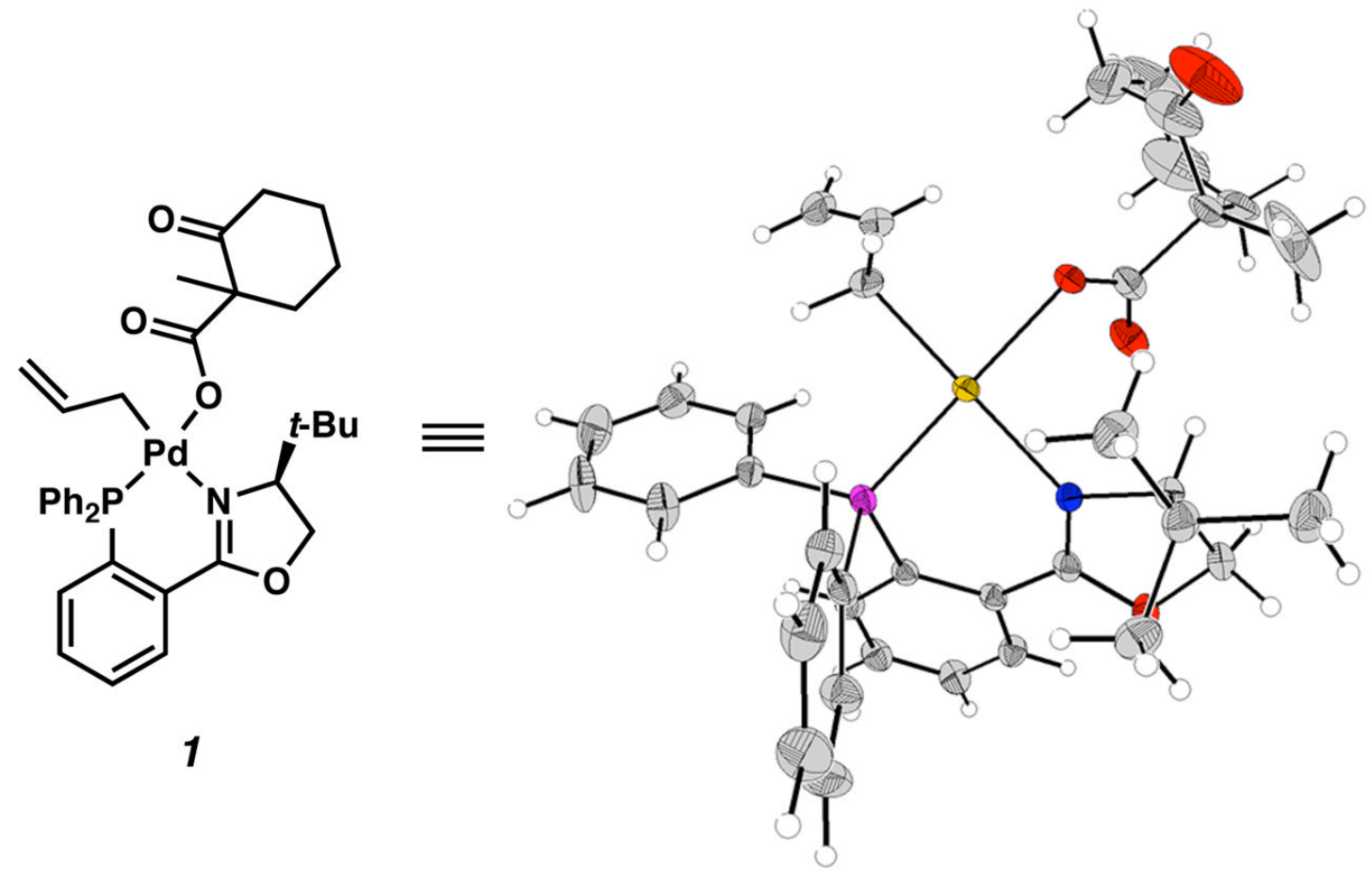

Figure 1.

$\mathrm{X}$-ray structure of complex $\mathbf{1}$ (one diastereomer shown), the resting state of the catalytic cycle. The molecular structure is shown with $50 \%$ probability ellipsoids. 

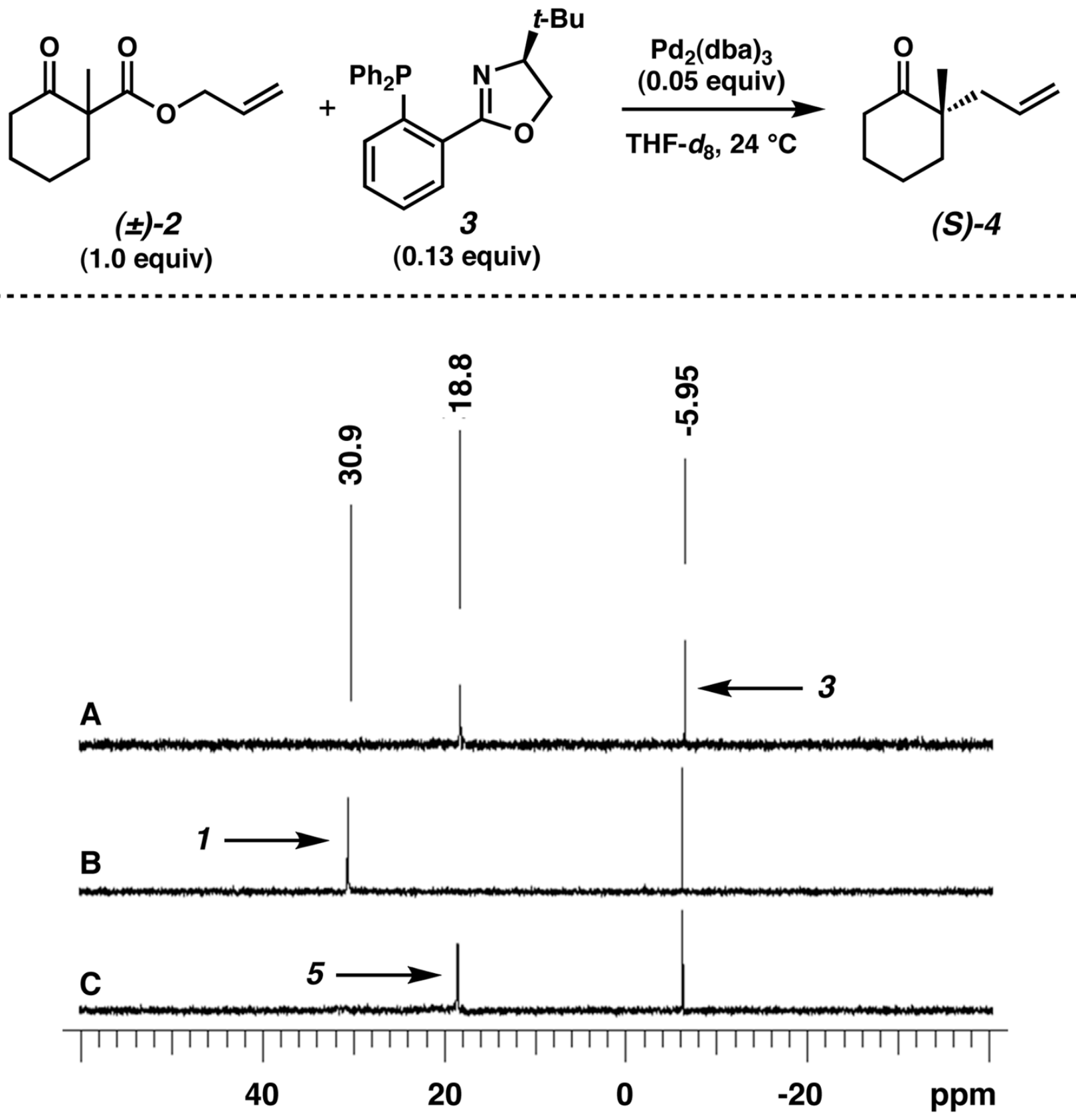

Figure 2.

${ }^{31} \mathrm{P}$ NMR study of the asymmetric allylic alkylation of $\beta$-ketoester ( \pm )-2. A) Spectrum of ligand 3 and $\mathrm{Pd}_{2}(\mathrm{dba})_{3}$ in THF- $d_{8}$ after $30 \mathrm{~min}$. B) Spectrum after addition of $\beta$-ketoester ( \pm )-2 to the above mixture. C) Spectrum after completion of the reaction to form ketone 4. Spectra referenced to $85 \%$ aq $\mathrm{H}_{3} \mathrm{PO}_{4}, \delta 0.0 \mathrm{ppm}$. 

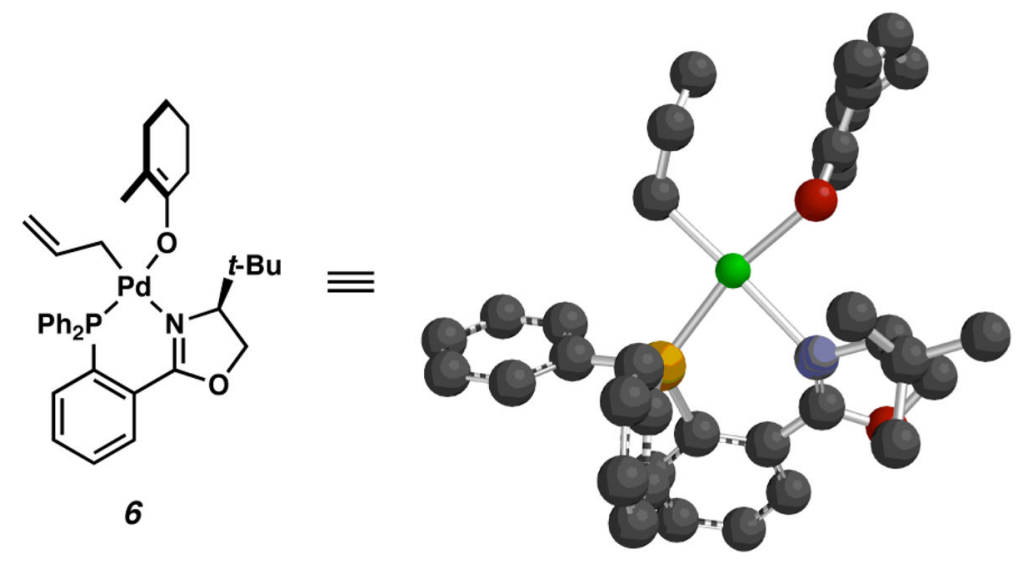

Figure 3.

DFT-calculated intermediate $\eta^{1}$-allyl Pd-enolate, prior to $\mathrm{C}-\mathrm{C}$ bond-forming reductive elimination.[3] Hydrogen atoms have been removed for clarity. 


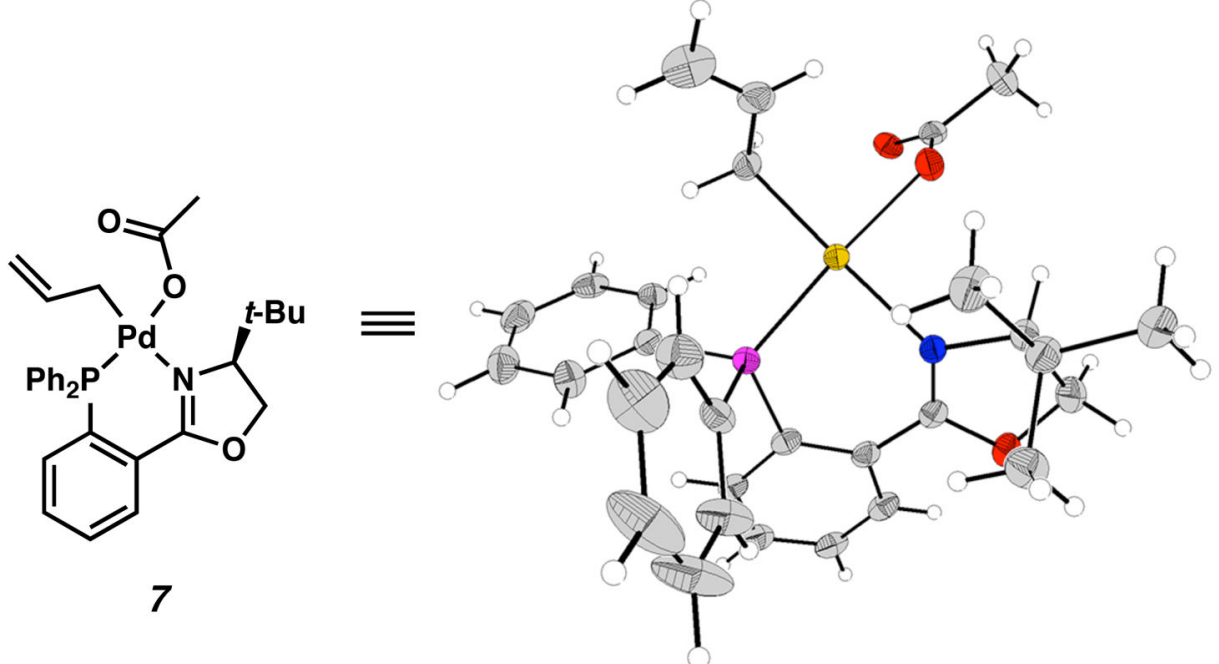

Figure 4.

$\mathrm{X}$-ray structure of acetate $\mathbf{7}$ (one conformation represented). The molecular structure is shown with $50 \%$ probability ellipsoids. 


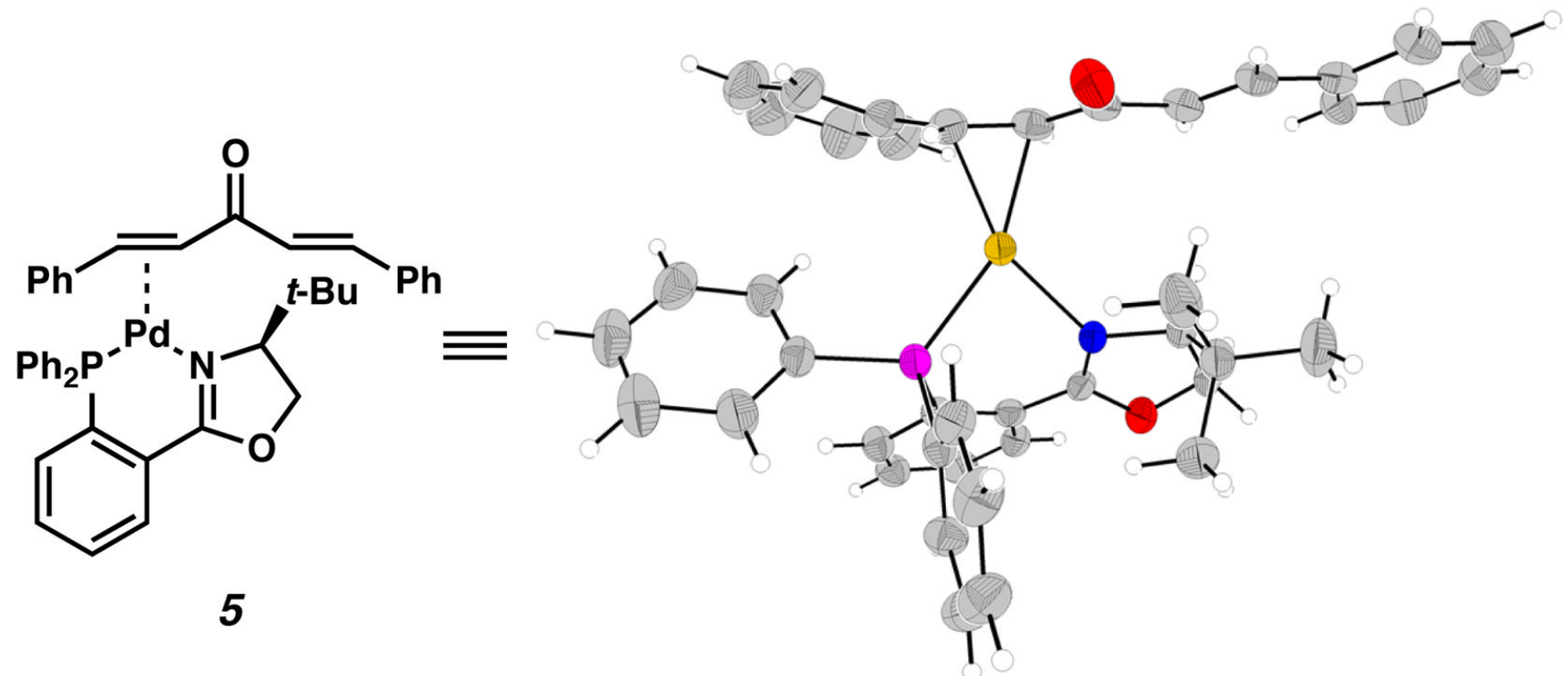

Figure 5.

X-ray structure of adduct 5 . The molecular structure is shown with $50 \%$ probability ellipsoids. [6] 
<smiles>[R]C(=C)COC(=O)[Z]1([R])CCCC([R])(C(=O)OCC([R])=C)C(=O)C1</smiles>

Scheme 1.

Palladium-catalyzed enantioselective decarboxylative allylic alkylations of ketone enolates. $\mathrm{dba}=$ trans,trans-dibenzylideneacetone. 


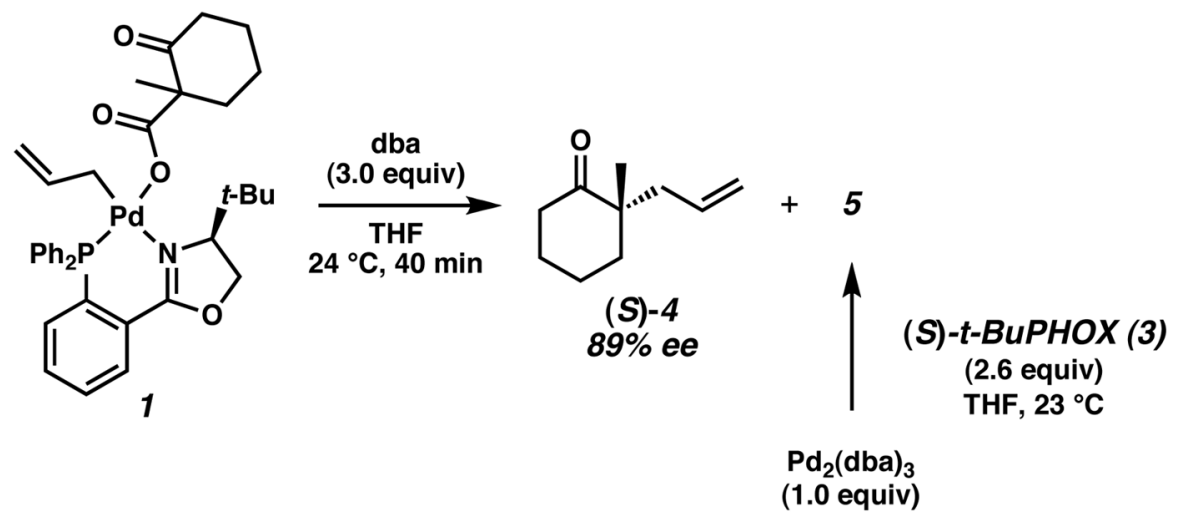

Scheme 2.

Thermal decomposition of complex $\mathbf{1}$ in the presence of dba and the independent synthesis of 5. 


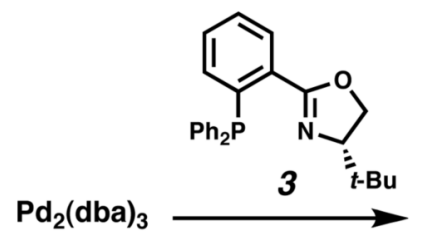

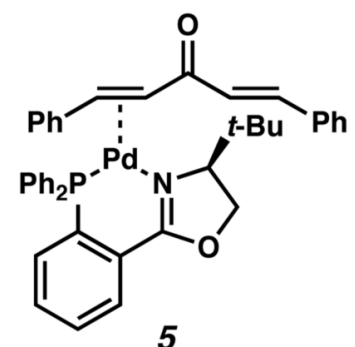

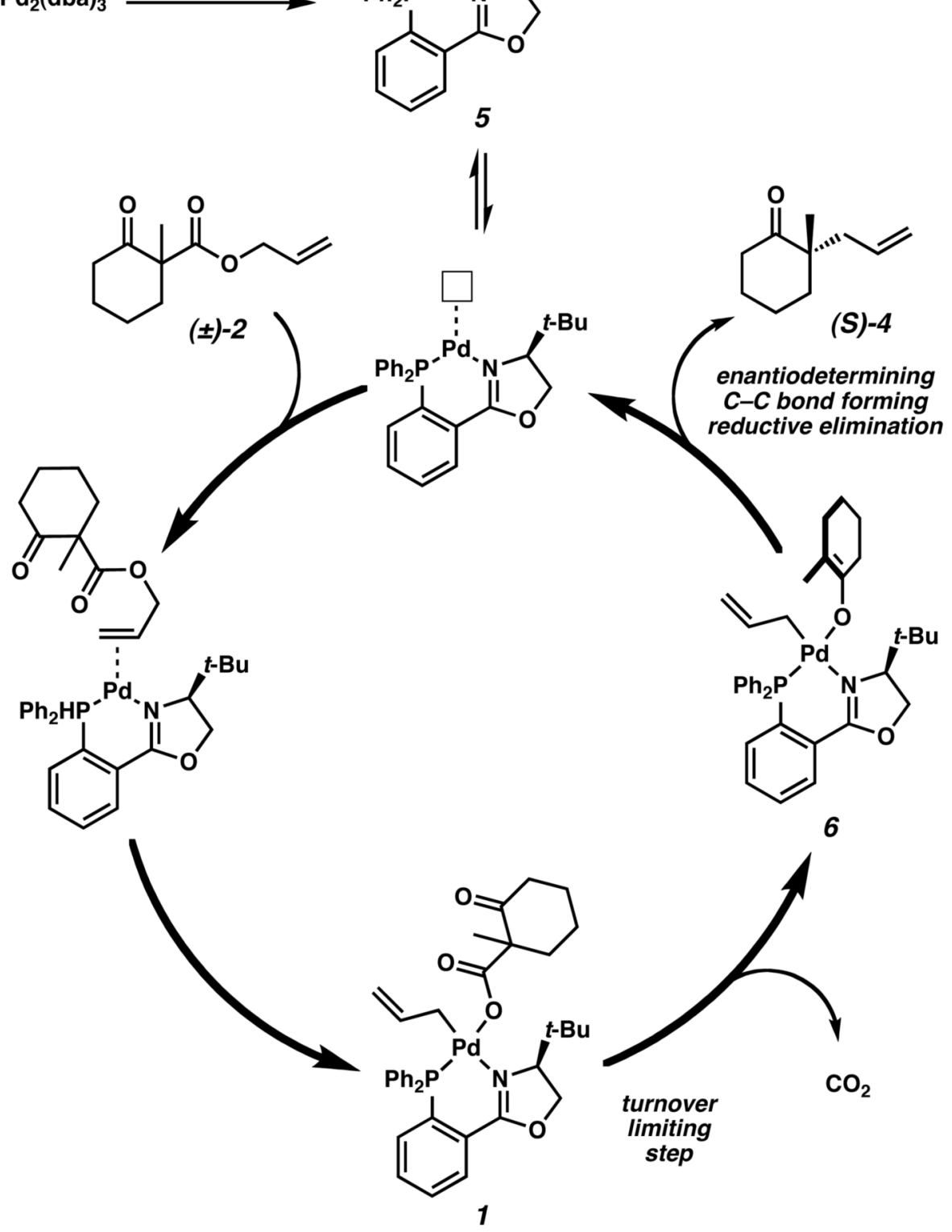

Scheme 3.

Proposed mechanism. 